-or that the diuretic has been thoughtlessly injected into oedematous tissues, from which the drug is absorbed only slowly. Loop diuretics bind strongly to plasma protein and their effectiveness depends on the peak plasma concentration of free drug: any dose given once daily is likely to be more than twice as effective as half the dose given twice daily. Protein binding is reduced both in patients with hypoalbuminaemia and in those with uraemia; and competition between diuretics and other strongly protein-bound drugs, such as warfarin and clofibrate, can substantially increase the free concentrations of those drugs. The doses of other drugs may therefore have to be reduced.

Infusing salt-poor albumin at the same time as giving a large dose of diuretic may trigger diuresis in patients with severe hypoproteinaemia. ${ }^{2}$ The increase in plasma albumin concentration is only small and transient in those with severe nephrosis, but it may be just enough to turn on the tap. Once diuresis begins, the doses of diuretics must usually be rapidly and substantially decreased to prevent excessive loss of salt and water, a sufficient diuresis being maintained by a much smaller dose than is required to initiate it.

A net loss of more than 1 litre of fluid daily (best judged from body weight) is potentially dangerous for patients with chronic oedema because it takes many hours to mobilise the fluid from oedematous tissue, especially if the plasma albumin concentration is low, and the plasma thus bears the brunt of the loss at first. A sudden and profound fall in plasma volume may precipitate oliguric renal failure in patients with hypoalbuminaemia, and in patients with cardiac failure substantially reduce a cardiac output that has long depended on a high venous filling pressure.

Oedema occasionally resists full diuretic treatment in intractable chronic heart failure and cirrhosis, and very occasionally in nephrosis. For most of these patients the outlook is bleak whether or not the oedema is removed mechanically, though we can sometimes break the vicious cycle of chronic heart failure by infusing dopamine to increase cardiac output and also renal blood flow and sodium excretion. ${ }^{3}$ Severe proteinuria can be quickly reduced only when caused by minimal-change nephropathy, but it tends gradually to diminish whatever the cause; hypoproteinaemia due to cirrhosis is less likely to improve. But, while remedying the primary cause, so far as possible, we must also attack the consequent renal sodium and water retention in its own right. Bed rest and a low-sodium diet are important adjuncts in difficult cases (though unnecessary in most oedematous patients). Water intake matters only if plasma sodium concentration falls, in which case it must be restricted enough to restore the sodium concentration to normal.

Ultrafiltration dialysis ${ }^{45}$ is the treatment of choice for the few patients who are likely to have a new lease of life after losing the resistant oedema, and for those who have rapidly accumulated oedema by therapeutic misadventure and can be treated quickly with safety. Resistant ascites in patients with cirrhosis who have no generalised oedema is probably best treated by the ingenious peritoneojugular shunt of Le Veen ${ }^{6}$ rather than ultrafiltration of ascitic fluid. But if we are careful to prevent salt and water overload and use diuretics aggressively such heroic measures are hardly ever necessary.

1 Allison, M E M, and Kennedy, A C, Clinical Science, 1971, 41, 171.

${ }^{2}$ Davison, A M, et al, British Medical fournal, 1974, 1, 481.

${ }^{3}$ Rosenblum, R, and Frieden, J, American Heart fournal, 1972, 83, 743.

4 Silverstein, M E, et al, New England Fournal of Medicine, 1974, 291, 747.

5 Asaba, H, et al, Acta Medica Scandinavica, 1978, 204, 145.

6 Wapnick, S, et al, fournal of the American Medical Association, 1977, 237, 131.

\section{Tumour antigens and optimism}

If a subject's worth can be judged by its pedigree then the concept of specific immunotherapy has much to recommend it. Its origins date back to 1890, when von Behring and Kitasato $^{1}$ discovered antibody against the diphtheria toxinand little imagination was needed to translate this discovery into a potential means by which the host might challenge the cancer cell. So great was the enthusiasm among researchers that by 1929 Woglom $^{2}$ could review critically some 600 publications on immunity to transplantable tumours; and he concluded that immunity to such tumours was "a generalised refractory condition which appears entirely unrelated to other forms of immunity."

Further development of research on syngeneic animal populations eventually showed that chemically induced tumours have individually specific tumour antigens, while virally induced tumours share common tumour-specific antigens. Increasingly refined investigative techniques have elaborated these simple observations, both qualitatively and quantitatively. Burkitt's theories of clonal selection seemed to provide an explanation for the development of neoplasia, and an attractive feature of his interpretation was that a cancer might originate from a single cell and give rise to a daughter population (clone) of cells, which, if sufficiently distinct antigenically from the normal tissue, would make their eradication immunologically feasible. Therein lies the bait, for, if the theories are valid, cure lies close by. Unfortunately, conclusive evidence of specific immune reactivity has proved remarkably elusive both in spontaneously arising tumours in animals and in human cancer.

Nevertheless, man's therapeutic ego is not easily daunted, so that not only is immunotherapy of every kind widely practised but physicians choose to specialise in its application and journals devoted to its exposition proliferate. Yet, in addition to our failure to demonstrate immunologically relevant tumour-specific antigens, the past 10 years has also seen too many therapeutic disappointments.

Among the many possible immunotherapeutic manipulations most interest has focused on active forms of immune stimulation. Specific active immunotherapy has obvious appeal. Some encouragement for this optimism came from the results of laboratory work showing that autoimmunisation can increase lymphocyte cytotoxicity against autologous melanoma cells. ${ }^{3}$ Later studies showed that a decrease in serum inhibitor activity contributed to the increase in lymphocyte cytotoxic activity. ${ }^{4}$ Although melanoma ${ }^{5}{ }^{6}$ was a popular disease for study, similar types of immunotherapy were used in many other tumours. ${ }^{7}$ Nevertheless, the initial optimism was tempered in carefully qualified reviews suggesting benefit only after statistical analysis of comparative trials.

This difficulty in showing a satisfactory response was attributed to poor immunogenicity of the tumour antigen. Attempts were made to heighten its immunogenicity by digesting the cell membrane with neuraminidase, ${ }^{8-12}$ by extracting the cell membranes, ${ }^{13}$ or by viral modification of the cell ${ }^{14}$; but (with the exception of acute myelogenous leukaemia $^{15}$ ) the results have proved disappointing. For example, after the study of specific active immunotherapy in patients receiving intermittent cytotoxic chemotherapy as an adjuvant to surgery in stage IIB malignant melanoma Hedley et al ${ }^{\mathbf{1 6}}$ advised caution. Sixteen treated patients had a median relapse-free interval of five months, compared with eight 
months in those who received the same chemotherapy together with BCG. In the group receiving specific active immunotherapy most relapses were in the lymphatic drainage area of the primary tumour, unlike in the controlled group, whose relapses were at distant sites. An earlier study ${ }^{17}$ reported a similar trend to relapse early in patients receiving immunotherapy with BCG and irradiated cells.

These reports emphasise that we should be cautious in setting up new immunotherapy trials and that the results of existing trials should be studied critically in the light of what we know. More important, we need further laboratory studies to examine the principles which justify immunotherapy in treatment. Until we have such results, Woglom's observation ${ }^{2}$ of 50 years ago remains essentially true.

\footnotetext{
${ }^{1}$ Behring, E, and Kitasato, S, Deutsche Medizinische Wochenschrift, 1890, 16, 1113.

2 Woglom, W H, The Cancer Review, 1929, 4, 129.
}

${ }^{3}$ Currie, G A, LeJeune, F, and Fairley, G H, British Medical fournal, 1971, 2, 305.

4 Currie, G A, British fournal of Cancer, 1973, 28, 25.

5 Currie, G A, and McElwain, T J, British fournal of Cancer, 1975, 31, 143.

6 Gutterman, J U, et al, Seminars in Oncology, 1975, 2, 155.

${ }^{7}$ Holmes, E C, Eilber, F R, and Morton, D L, fournal of the American Medical Association, 1975, 232, 1052.

${ }^{8}$ Miller, E E, et al, fournal of Surgical Oncology, 1976, 8, 31

${ }^{9}$ Cunningham, T J, et al, Annals of the New York Academy of Sciences, 1976, 277, 339.

${ }^{10}$ Rosato, F E, et al, Annals of the New York Academy of Sciences, 1976, 277, 332.

11 Rosato, F E, Miller, E, and Rosato, E F, Virginia Medical Monthly, 1978, 105, 221.

12 Rosato, F E, et al, Surgery, Gynecology and Obstetrics, 1974, 139, 675

13 Stewart, T H M, et al, Canadian fournal of Surgery, 1977, 20, 370.

14 Green, A A, et al, Annals of the New York Academy of Sciences, 1976, 277, 396.

15 Bekesi, J G, et al, Proceedings of the American Association for Cancer Research and American Society of Clinical Oncology, 1976, 17, 184.

${ }^{16}$ Hedley, D W, McElwain, T J, and Currie, G A, British fournal of Cancer, $1978,37,491$.

17 McIllmurray, M B, et al, British Medical fournal, 1977, 1, 540.

\section{Menetrier's disease}

Menetrier's disease is a good example of the inverse relation between the incidence of a disorder and the interest it generates. ${ }^{1-3}$ This curious disease-characterised by gross mucosal hypertrophy, hyposecretion of gastric acid, excess loss of protein from the stomach, diminished gastric motility, oedema, weight loss, anorexia, nausea and vomiting, and sometimes diarrhoea-is exceedingly rare, yet we understand its natural history, complications, and management better than those of more common gastric diseases.

The disorder is about three times more common in men than women, being most often diagnosed in people between 30 and 50. It does not appear to be directly inherited and is almost certainly acquired in adult life, though the history of symptoms often extends over many years. A similar but possibly distinct disorder has been reported in children. Patients may have a higher-than-average incidence of cardiovascular thrombotic disease, which may in turn contribute to their increased death rate, and probably an increased risk (similar to that in atrophic gastritis) of both primary and secondary carcinoma of the stomach. Some reports have noted various allergies.

The mucosal changes are gross, and both barium meal $x$-ray films and inspection by the naked eye at operation show large, heaped-up folds like the convolutions of the brain. The changes affect either parts of the stomach or the entire organ, generally being greatest in the fundus with relative sparing of the antrum. Full-thickness biopsy specimens should be taken at endoscopy. Microscopically, these show proliferation of all mucosal cells, but of the mucus-secreting more than the parietal and pepsin cells. There may also be lymphoid hyperplasia.

Although we do not know what causes this alteration of the mucosa, two interesting hypotheses are suggested by the results of recent investigations. Firstly, certain hormones of the upper gastrointestinal tract (for example, gastrin) exert a direct trophic effect on the gastric mucosa, and an exaggerated mucosal response might result from a disorder of this trophic mechanism. ${ }^{4}$ Secondly, the mucosal proliferation may be a response to excessive regurgitation of the contents of the small intestine through the pylorus. The possibly harmful effect of bile salts, lysolecithin, and other constituents as a factor in gastric ulcer and the disorders that follow gastric surgery have received much attention, and du Plessis $e t$ al have emphasised that structural damage to the gastric mucosa may result. $^{5}$ If this is an important factor in Menetrier's disease, however, there should be greater changes in the antral mucosa.

Many of the clinical features are due to the large losses of water, electrolytes, and protein from the gastric mucosa. Most patients have serum concentrations of albumin under $35 \mathrm{~g} / \mathrm{l}$, while loss of immunoglobulin may impair the immune defences. Not surprisingly, the symptoms usually resist medical measures such as diet, antacids, and anticholinergics; and virtually all patients not treated by resection have chronic symptoms. But if specific antagonists to gastrointestinal hormones were developed they would be worth evaluating in view of these hormones' possible role in the disease. Irradiation to control the hyperplastic mucosa has given more unsatisfactory than good results. Understandably, surgeons are reluctant to advocate total gastrectomy, but partial resection yields a higher incidence of leaks from anastomoses than it does in peptic ulcer disease-possibly from suturing unhealthy gastric tissue. Total gastrectomy gives appreciably better results in this disorder than in gastric cancer, and, since it effectively eliminates the disease and abolishes the drain on protein and non-acid secretions, it seems to be the operation of choice-which removes the potential source of malignancy as an additional benefit.

Thus, just as in the Zollinger-Ellison syndrome, all we can offer sufferers, despite knowing so much about the mechanisms of the disease, is extirpation of the target organ. Nevertheless, we hope that we may soon be able to correct the deranged physiological machinery by some specific and effective pharmacological means.

1 Scharschmidt, B F, American fournal of Medicine, 1977, 63, 644.

2 Davis, J M, Gray, G F, and Thorbjarnarson, B, Annals of Surgery, 1977, $185,456$.

${ }^{3}$ Berenson, M M, Sannella, J, and Freston, J W, Gastroenterology, 1976, 70, 257.

4 Johnson, L R, in Gastrointestinal Hormones, ed J C Thompson, p 215. Austin, University of Texas Press, 1975.

5 Du Plessis, D J, in Topics in Gastroenterology-5, ed S C Truelove and E Lee, p 239. Oxford, Blackwell Scientific Publications, 1977. 